\title{
INVESTIGATION OF ELECTROCHEMICAL PROPERTIES OF CHEMICALLY SYNTHESIZED NICKEL DOPED ZINC OXIDE NANORODS
}

\author{
G. M. Lohar* A. S. Shelke, O. C. Pore, D. V. Rupnavar, C. P. Mane, R.V. Shejwal
}

Lal Bahadur Shastri College of Arts, Science

and Commerce, Satara 415002 M.S. India.

Email: gauravlohar24@gmail.com

Contact number: +91-9604695030

Communicated : 12.07 .19

Revision :21.07.19 \& 21.08.19

Accepted : 14.09.19

Published: 30.09 .19

\begin{abstract}
In the present study, $\mathrm{ZnO}$ nanorods are deposited using the chemical bath deposition (CBD), and structural, morphological, electrochemical properties are investigated. After synthesis of $\mathrm{ZnO}$ nanorods, different percentages of $\mathrm{Ni}$ atoms are doped in $\mathrm{ZnO}$ nanorods. The structural properties are studied using the x-ray diffraction spectroscopy, fourier transform infrared spectroscopy. The morphological properties are studied using the field emission scanning electron microscopy. The electrochemical properties are studied using the electrochemical impedance spectroscopy and using cyclic voltammetry.
\end{abstract}

Keywords: Zinc oxide, Nanorods, Chemical bath deposition

\section{INTRODUCTION:}

Zinc oxide $(\mathrm{ZnO})$, a typical II-VI compound semiconductor with a direct wide bandgap of $3.37 \mathrm{eV}$ and large exciton binding energy of 60 $\mathrm{meV}$ at room temperature, is regarded as a promising material in applications of shortwavelength optoelectronic devices [1-3]. Moreover, due to its superior conducting properties based on intrinsic defects, $\mathrm{ZnO}$ has been investigated as transparent conducting and piezoelectric materials for fabricating solar cells, electrodes, and sensors. Generally, $\mathrm{ZnO}$ reveals n-type conduction with a typical carrier concentration of $1017 / \mathrm{cm} 3$,which is smaller than the carrier concentration of 1018$1020 / \mathrm{cm}^{3}$ in laser diode applications [4-6]. To enhance the electrical properties, $\mathrm{ZnO}$ was frequently doped with many metal ions like Nickel and chromium [7-8].As far as the electrochemical properties, Zinc oxide have used in a photoelectrochemical solar cell [9], super capacitor [10] as well as batteries [11].

The $\mathrm{ZnO}$ nanorods is an active material for the electron-conducting pathway and excellent mechanical support. Many research groups developed $\mathrm{ZnO}$ based nanorods from different methods and applications. Efafi et al. [12] have synthesized $\mathrm{ZnO}$ nanorods for Photoluminescence application by considering the thermodynamic Parameters. Chandrasekhar et.al [13] are developed High efficient perovskite solar cells using $\mathrm{ZnO}$ nanorods as well as a prepared electron transport layer. Gao et al. [14] enhanced gas-sensitivity and ferromagnetism performances by the Nidoping $\mathrm{ZnO}$ nanorods. It also demonstrates that the oxygen vacancies and transition metal ions creating bound magnetic polarons are responsible for the origin of ferromagnetism in $\mathrm{ZnO}$ nanorods.

In the present work, $\mathrm{ZnO}$ thin films are deposited using the chemical bath deposition, and structural, morphological, electrochemical properties are investigated. The structural properties are studied using the $\mathrm{x}$-ray diffraction spectroscopy, and it shows the hexagonal structure. Also, fourier transform infrared spectroscopy employed to understand the structural investigation. The morphological properties are studied using the field emission scanning electron microscopy, and hexagonal nanorods are observed. The electrochemical properties are studied using the electrochemical impedance spectroscopy and using cyclic voltammetry. The efforts are deviated to understand the electrochemical properties than can have used for supercapacitor applications. 


\section{EXPERIMENTAL:}

All reagents used for the experiment are analytical grade. First, $50 \mathrm{ml}$ of $0.1 \mathrm{M}$ zinc acetate was prepared in double-distilled water. The ammonia solution was used to maintain the $\mathrm{pH}$ 11 of the zinc acetate solution. The whole system was kept in a water bath, which maintained at constant temperature $90^{\circ} \mathrm{C}$ for 2 hours. After removing the substrates from a reaction bath. These films were dried at room temperature for two hours and annealed afterward at $400^{\circ} \mathrm{C}$ for 4 h. The Nickel ions are doped in $\mathrm{ZnO}$ with different percentages of $\mathrm{Ni}$ atoms. For the doping, $\mathrm{Ni}$ nickel acetate was used. The four percentage is used to deposit the samples such as $0 \%, 1 \%$, $2 \%$, and $2.5 \%$ of Nickel nitrate. The four films draw at a different percentage of $\mathrm{Ni}$ atoms and names given as $\mathrm{A}, \mathrm{B}, \mathrm{C}$, and $\mathrm{D}$, respectively.

\section{RESULTS AND DISCUSSION:}

\subsection{X-ray diffraction \& fourier transform infrared spectroscopic study-}

Fig. 1 shows the structural properties of $\mathrm{ZnO}$ and $\mathrm{Ni}$ doped $\mathrm{ZnO}$ nanorods. Fig. 1 (a) shows the XRD pattern of $\mathrm{ZnO}$ nanorods. The observed d spacing values of $\mathrm{ZnO}$ well agreed with standard values (JCPDS: 00-036-1451). The $\mathrm{ZnO}$ nanorods having hexagonal structure with $a=b=3.24 A^{\circ}, c=5.20 A^{\circ} \& a=\beta=90^{\circ} \& \gamma=120^{\circ}$. Fig. $1(\mathrm{~b})$ shows the crystal structure of $\mathrm{ZnO}$ nanorods developed using observed XRD and standard JCPDS data from space group P63mc. Fig. 1 (c) show the polyhedral of $\mathrm{ZnO}$ nanorods. The FTIR spectra are a vital characterization tool for finding atomic and molecular bonding in nanomaterials. Fig. 1 (d) shows the FTIR spectra of Ni-doped $\mathrm{ZnO}$ nanorods. The FTIR spectra are recorded for samples $\mathrm{A}, \mathrm{B}, \mathrm{C}$, and $\mathrm{D}$. The peak at $528 \mathrm{~cm}^{-1}$ is belongs to the characteristic vibration of $\mathrm{Zn}-\mathrm{O}$. The peak near about $3500 \mathrm{~cm}^{-}$ ${ }^{1}$ has belonged to the $\mathrm{O}-\mathrm{H}$ group. As a $\mathrm{Ni}$ doping percentage increases in $\mathrm{ZnO}$, change has been observed in the intensity of $\mathrm{ZnO}$ peaks [13, 15].

\subsection{Field Emission Scanning Electron Microscopy-}

The FESEM, a tool, is used to investigate the morphology of $\mathrm{ZnO}$ thin film. Fig. 2 shows the FESEM images of $\mathrm{ZnO}$ nanorods with different percentages of Ni. Fig, 1 (A) shows the FESEM image of pure $\mathrm{ZnO}$; it shows the hexagonal nanorods like morphology of $\mathrm{ZnO}$.
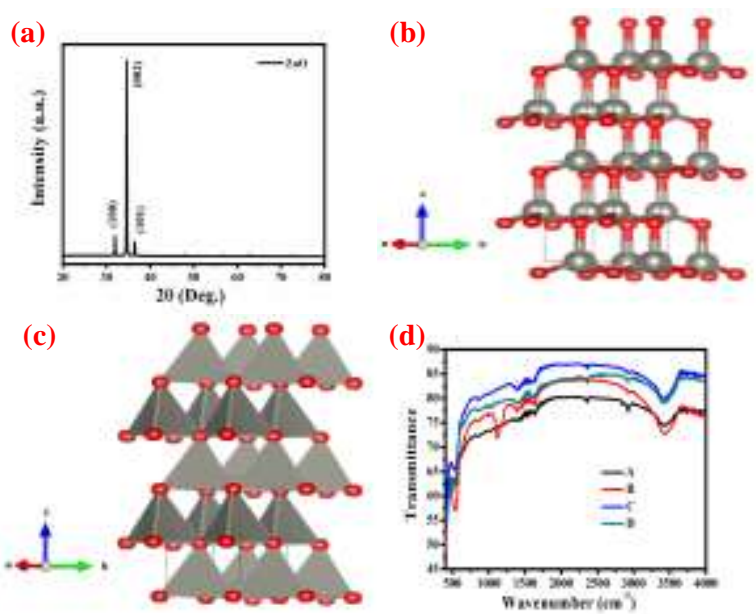

Fig. 1 structural properties of Ni-doped $\mathrm{ZnO}$ thin film, (a) XRD pattern of $\mathrm{ZnO}$, (b) crystal of $\mathrm{ZnO}$ developed using XRD pattern, (c) polyhedron of $\mathrm{ZnO}$ developed using the XRD, (d) FTIR spectra of Ni-doped $\mathrm{ZnO}$ thin film

The hexagonal nanorods are having a width of $250 \mathrm{~nm}$, and these results are consistent with XRD results. Fig.1 (B) shows the 1\% Ni-doped $\mathrm{ZnO}$, after the doping of Nickel, The size of a head of a nanorod is decreased, and the width and length of rods are observed to be increased. Fig. 2 (C) shows the $2 \% \mathrm{Ni}$-doped $\mathrm{ZnO}$ nanorods, the nanorods are well organized and shows the flower-like nature. At $2.5 \%$ of nickel, the $\mathrm{ZnO}$ rods also shows flower-like nature with a little bit over growth shown in Fig. 2 (D). Also, mostly the nanorods are developed becouse seed layes as well as grouth in $Z$ direction only [16-17]

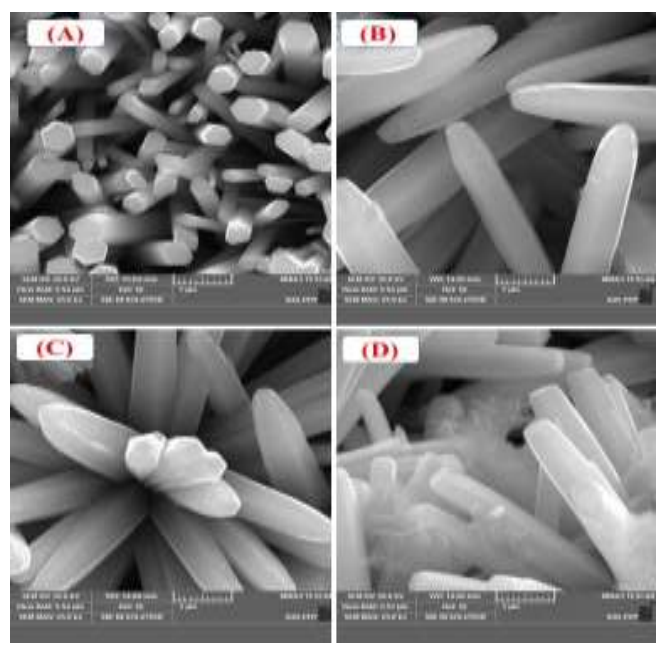

Fig. 2 FESEM images of Ni-doped $\mathrm{ZnO}$ nanorods with different percentages of nickel.

\subsection{Electrochemical Impedance spectroscopic study-}


The electrochemical impedance spectroscopy is a tool used to investigate the charge transfer process at the solid-liquid interface [18-19]. The solution resistance, charge transfer resistance, capacitance, and Warburg coefficient is calculated from results. The Fig. 3 shows the Nyquist plot and equivalent circuit diagram. The parameters calculated from the circuit diagram have mentioned in Table. 1. Table. 1 shows the near about the same value of charge transfer resistance and higher values of charge transfer resistance.
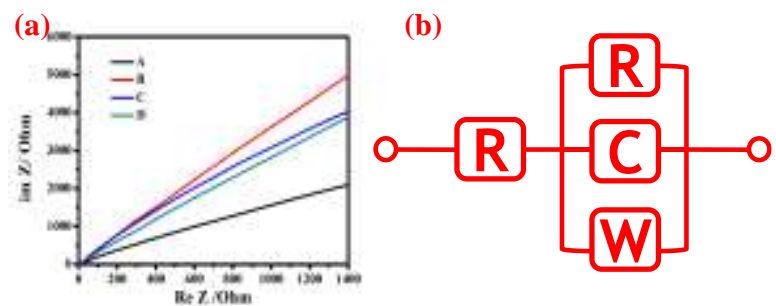

Fig. 3 EIS study of Ni-doped ZnO, (a) Nyquist plot of Ni-doped ZnO, (b) Equivalent circuit diagram for Ni-doped $\mathrm{ZnO}$

Table 1 Observed parameters from EIS

\begin{tabular}{|c|l|c|c|c|}
\hline $\begin{array}{c}\text { Samples } \\
\text { parameters }\end{array}$ & $\mathrm{R} 1(\Omega)$ & $\begin{array}{c}\mathrm{C} \\
(\mu \mathrm{F})\end{array}$ & $\mathrm{R} 2(\Omega)$ & $\mathrm{W}\left(\Omega . \mathrm{s}^{1 / 2}\right)$ \\
\hline $\mathrm{ZnO}$ & 15.08 & 4.26 & $\begin{array}{c}0.388 \mathrm{x} \\
10^{18}\end{array}$ & $1.28 \times 10^{12}$ \\
\hline $\begin{array}{c}1 \% \mathrm{Ni} \text { doped } \\
\mathrm{ZnO}\end{array}$ & 10.36 & 4.20 & $\begin{array}{c}0.299 \mathrm{x} \\
10^{21}\end{array}$ & $3.47 \times 10^{12}$ \\
\hline $\begin{array}{c}2 \% \mathrm{Ni} \text { doped } \\
\mathrm{ZnO}\end{array}$ & 10.93 & 1.51 & $\begin{array}{c}4.51 \mathrm{x} \\
10^{18}\end{array}$ & $0.202 \times 10^{12}$ \\
\hline $\begin{array}{c}2.5 \% \mathrm{Ni} \\
\text { doped } \mathrm{ZnO}\end{array}$ & 12.78 & 3.43 & $\begin{array}{c}0.509 \\
\mathrm{x} 10^{22}\end{array}$ & $1.65 \times 10^{12}$ \\
\hline
\end{tabular}

\subsection{Cyclic voltammetry study-}

The cyclic voltammetry $(\mathrm{CV})$ is a powerful and popular electrochemical technique commonly employed to investigate the reduction and oxidation processes of molecular species. The cyclic voltammetry study is shown in Fig. 4 (a,b,c,d) for pure $\mathrm{ZnO}, 1 \%, 2 \%$, and $2.5 \% \mathrm{Ni}$ dopedZnO nanorods, respectively. Fromfig. 4 , it is observed that the maximum current and area under the curve is observed for $1 \% \mathrm{Ni}$-doped $\mathrm{ZnO}$. The $1 \% \mathrm{Ni}$-dopedZnO sample shows more area under the curve than other deposited samples. It indicates that $1 \%$ of $\mathrm{Ni}$-doped $\mathrm{ZnO}$ samples are more useful for supercapacitor applications. The $1 \% \mathrm{Ni}$-doped $\mathrm{ZnO}$ nanorods can produce more current than other doped, undoped $\mathrm{ZnO}$ Samples.
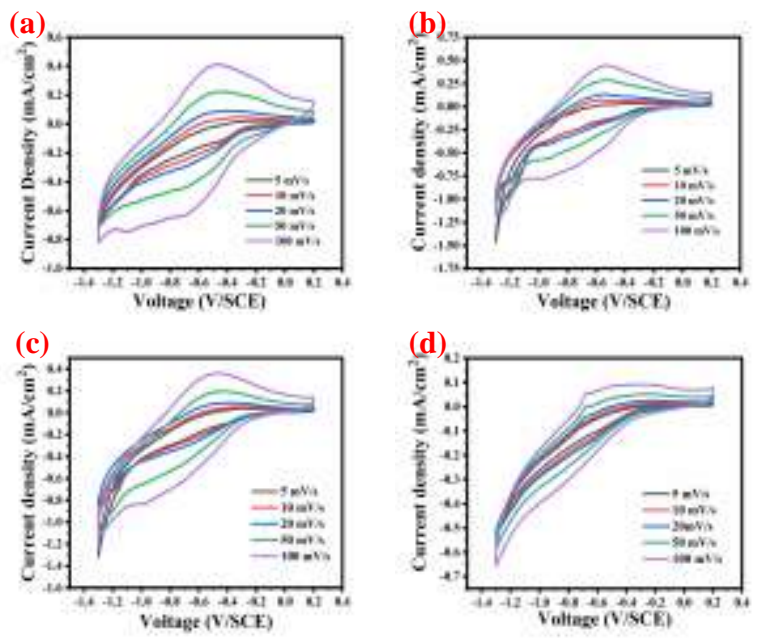

Fig. 4 Cyclic voltammetry study forNidopedZnO sample for different scan rate, (a) for $\mathrm{ZnO}$ sample, (b) for $1 \%$ Ni-doped $\mathrm{ZnO}$ sample, (c) $2 \% \mathrm{Ni}$ doped $\mathrm{ZnO}$ sample, (d) for 2.5\% Ni doped $\mathrm{ZnO}$ sample

\section{CONCLUSION:}

In conclusion, the $\mathrm{ZnO}$ nanorods are successfully synthesized using the chemical bath deposition technique. The well organized and nicely developed $\mathrm{ZnO}$ nanorods are synthesized. X-ray diffraction study reveals the hexagonal structure and consistent with FEEM results. The FTIR study shows the peak at 528 $\mathrm{cm}^{-1}$, shows the characteristic vibration of $\mathrm{Zn}-\mathrm{O}$. The FESEM study indicates that successfully synthesized $\mathrm{ZnO}$ nanorods. The EIS study exposed all ionic processes. The cyclic voltammetry study shows the more area under the curve for $1 \% \mathrm{Ni}$ doped $\mathrm{ZnO}$ nanorods. In conclusion, $1 \%$ of $\mathrm{Ni}$-doped nanorods are useful for supercapacitors as well as $1 \% \mathrm{Ni}$ doping is useful for improving the electrochemical properties.

\section{AKNOWLEDGEMENT:}

Dr. G. M. Lohar thankful to college incubation centre for providing fund research work

\section{REFERENCES:}

K.R. Nandanapalli, D. Mudusu, Surface passivated zinc oxide $(\mathrm{ZnO})$ nanorods by atomic layer deposition of ultrathin $\mathrm{ZnO}$ layers for energy device applications, ACS Appl. Nano Mater. 1 (2018) 4083-4091 
Y.-J. Choi, S.C. Gong, C.-S. Park, H.-S. Lee, J.G. Jang, H.J. Chang, G.Y. Yeom, H.H. Park, Improved performance of organic light-emitting diodes fabricated on Al-doped $\mathrm{ZnO}$ anodes incorporating a homogeneous Aldoped $\mathrm{ZnO}$ buffer layer grown by atomic layer deposition, ACS Appl. Mater. Interfaces 5 (2013) 3650-3655

S. Banerjee, M. Mandal, N. Gayathri, M. Sardar, Enhancement of ferromagnetism upon thermal annealing in pure $\mathrm{ZnO}$, Appl. Phys. Lett. 91 (18) (2007) 182501.

Cui Y, Wei Q, Park H and Lieber C M 2001 Nano wire nano sensors for highly sensitive and selective detection of biological and chemical species Science 2931289

Xia Y N, Yang P D, Sun Y G, Wu Y Y, Mayers B, Gates B, Yin Y D, Kim F and Yan H Q $2003 \quad$ One-dimensional nanostructures: synthesis, characterization, and applications Adv. Mater. 15353

Duan X F, Huang Y, Cui Y, Wang J F and Lieber C M 2001 Indium phosphide nano wires as building blocks for nano scale electronic and optoelectronic devices Nature 40966

Qianqian Gao, Yuqiang Dai, Bingquan Han, Wenlu Zhu, Xianchang Li, Chengbo Li, Enhanced gas-sensitivity and ferromagnetism performances by the Nidoping induced oxygen vacancies in (Mn, Ni) codoped $\mathrm{ZnO}$ nanorods, Applied Surface Science 490 (2019) 178-187

M. Zhong, S. Wang, Y. Li, Y. Hu, M. Zhu, H. Jin, Y. Li, H. Zhang, H. Zhao, Room temperature ferromagnetic $\mathrm{Cr}-\mathrm{Ni}$ codoped $\mathrm{ZnO}$ diluted magnetic semiconductors synthesized by hydrothermal method under high pulsed magnetic field, Ceram. Int. 41 (1) (2015) 451-457

Yijie Wang, Min Zhong, Wu Wang, Qiuyu Wang, Wenduo Wu, Xingchuan Luo, Effects of ZnSe modification on the perovskite films and perovskite solar cells based on $\mathrm{ZnO}$ nanorod arrays, Applied Surface Science, 30 (2019) 143552

M. Selvakumar, D. Krishna Bhat, A. Manish Aggarwal, S. Prahladh Iyer, G. Sravani, Phys. B: Condens. Matter 405 (2010) 2286-2289.

J. Huang, Z. Yang, B. Yang, R. Wang, T. Wang, J. Power Sources 271 (2014) 143-151

Babak Efafi, Hamidreza Mazandarani, Mohamad Hossein Majles Ara, Bijan Ghafary, Improvement in photoluminescence behavior of wellaligned $\mathrm{ZnO}$ nanorods by optimization of thermodynamic parameters, Physica B: Condensed Matter, 579, 2020, 411915

P.S. Chandrasekhar, Ashish Dubey, Qiquan Qiao, High efficiency perovskite solar cells using nitrogendoped graphene/ZnO nanorod composite as an electron transport layer, Solar Energy 197 (2020) 78-83

Qianqian Gao, Yuqiang Dai, Bingquan Han, Wenlu Zhu, Xianchang Li, Chengbo Li, Enhanced gas-sensitivity and ferromagnetism performances by the Nidoping induced oxygen vacancies in (Mn, Ni) codoped $\mathrm{ZnO}$ nanorods, Applied Surface Science 490 (2019) 178-187

L.Vayssieres, Adv. Mater, 15, (2003) 464466

Berchi Abderrahmane, Abdi Djamila, Nacer Chaabia, Rahal Fodil, Improvement of $\mathrm{ZnO}$ nanorods photoelectrochemical, optical, structural and morphological characterizations by cerium ions doping, Journal of Alloys and Compounds, 829, (2020) 154498

R. Chander, A. K. Raychaudhuri. "Electro deposition of aligned arrays of $\mathrm{ZnO}$ nanorods in aqueous solution", Solid State Communications. 145 (12) (2008) 81-85

G.M. Lohar, S.T. Jadhav, M.V. Takale, R.A. Patil, Y.R. Ma, M.C. Rath, V.J. Fulari, Photo electrochemical cell studies of Fe2+doped ZnSe nanorods using the 
potentiostatic mode of electro deposition, Journal of Colloid and Interface Science 458 (2015) 136-146

G. M. Lohar, S. T. Jadhav, B. P. Relekar, R. A. Patil, Y. R. Ma, V. J. Fulari, Electrochemically synthesized 1D and 3D hybrid Fe3+dopedZnSe dandelions for photo electrochemical cell application, Optik 158 (2018) 53-63

A. V. Fulari, M. V. Ramana Reddy, S. T. Jadhav, G. S. Ghodake, D. Y. Kim, G.
M. Lohar, TiO2/reduced graphene oxide composite based nano-petalsfor supercapacitor application: effect of substrate, Journal of Materials Science: Materials in Electronics volume 29, pages 10814-10824(2018) AS Patil, MD Patil, GM Lohar, ST Jadhav, VJ Fulari, Super capacitive properties of $\mathrm{CuO}$ thin films using modified SILAR method, Ionics, 23, 12591266(2017) 